\title{
Twice vaccinated recipients are better protected against epidemic measles than are single dose recipients of measles containing vaccine
}

\author{
Mikko Paunio, Heikki Peltola, Martti Valle, Irja Davidkin, Martti Virtanen, \\ Olli P Heinonen
}

\begin{abstract}
Objective-To study measles risk after revaccination.

Design-A population-based case-control study during an epidemic season.

Main outcome measure-Relative serologically confirmed measles risk.

Participants and methods-153 vaccinated cases, mostly from rural areas, were serologically confirmed as measles at the central laboratory in 1988-89. A randomly selected group of 453 controls from either municipalities of vaccinated cases or from areas where measles attack rate was $>600$ / $10^{5}$, was identified via the population registry. Vaccination and measles histories of cases and controls were determined from official vaccination cards.

Results-Once and twice vaccinated had crude relative risk $\mathbf{1 5 . 6}$ and 2.3 compared with thrice vaccinated. When cases who had received their first vaccination at less than 14 months of age were omitted from analysis, once vaccinated had 4.0 (95\% CI 1.2, 16.6) times higher age adjusted measles risk compared with twice vaccinated. When, omission was extended to cases from one particular municipality where even revaccinees had high measles risk during an explosive outbreak the corresponding risk ratio was $17.8(2.8,67.8)$. Conclusions-Twice vaccinated have better protection against epidemic measles compared with single dose recipients. (F Epidemiol Community Health 1999;53:173-178)
\end{abstract}

Indisputable individual level evidence that measles revaccinations increase protection is still lacking, and there is little information upon which to base optimised revaccination schedules, ${ }^{1}$ though it has recently even internationally been recommended that there is a need to implement revaccinations against measles. $^{2}$

A two dose measles vaccination policy to improve coverage and correct sporadic primary vaccination failures ${ }^{3}$ (deficient seroresponse) was adopted by Finland in 1982..$^{4-6}$ This provides an exceptional opportunity to study the epidemiology of vaccine failures, against a background of decades of meticulously kept vaccination records, and effective serological surveillance of measles. We studied whether revaccinated people are better protected compared with single dose recipients in epidemic conditions, with an interest in waning immunity $^{7-9}$ (secondary vaccine failures; time since vaccination), and interval between vaccinations.

\section{Methods}

SETTING AND VACCINATION IN FINLAND

The setting for the study was the whole of Finland, an affluent Nordic country, with 5.1 million inhabitants.

In Finland, children are vaccinated free of charge by public health nurses at child health care centres. Each vaccination is registered on the child's health card kept at the centre and in a vaccination card kept at home. The health card is transferred from the centre to the school nurse when the child begins school.

All children born between 1973 and 1981 should have received the attenuated Schwarz strain measles vaccine (Rimevax, SmithKline Biologicals, Rixensart, Belgium), but only about $70 \%$ coverage was achieved. ${ }^{45}$ Preschool children born before 1973 also occasionally received this monovalent vaccine. Since 1982, the trivalent measles, mumps, and rubella vaccine (MMR II, Merck and Co, Inc, West Point, PA, distributed in Finland as Virivac, SBL Vaccine AB, Stockholm, Sweden) containing the More Attenuated Enders-Edmonston strain of measles virus has been used exclusively, and administered first at 14-18 months and again at 6 years. ${ }^{4-6}$ Thus children born between 1975 and 1981 were targets of both the monovalent and trivalent vaccination programmes, receiving the Schwarz strain at 14 months and exceptionally the first MMR at 2 to 5 years from 1983 to 1986 , and then the second MMR at six years. The interval required between successive MMR vaccinations was at least six months. There were 562000 children born between November 1975 and June 1984 under computerised surveillance. Non-vaccinated children aged 7-11 years were traced and vaccinated at schools in $1985 .{ }^{5}$ Since 1986, 19 year old conscripts have been targeted (table 1).

\section{OUTBREAK}

During the comprehensive national MMR vaccination programme measles became rare, but pockets of susceptible non-vaccinated people born mostly in the early 1970 s remained in rural sparsely populated areas. The last outbreak in Finland began in a municipality on the west coast after a 16 year old girl developed clinical measles on 15 September 1988. Next, a cluster of measles cases 
Table 1 Measles attack rate during the 1988-9 epidemic, and proportion of children daily meeting over nine other children or school mates

\begin{tabular}{|c|c|c|c|c|}
\hline Age & Daily attendance & $\begin{array}{l}\text { Proportion meeting } \\
\text { daily }>9 \text { children }\end{array}$ & $\begin{array}{l}\text { Attack rate } \\
\text { per } 10^{5}\end{array}$ & $M M R$ vaccination \\
\hline $0-9$ months & Home, maternal care & Low & 22.2 & - \\
\hline 9-13 months & Home, maternal care & Low & 306.7 & - \\
\hline 14-23 months & Day care or home & $6^{\star}$ & 98.0 & First \\
\hline 2 years & Day care or home & $14^{\star}$ & 23.3 & First† \\
\hline 3 years & Day care or home & $18^{\star}$ & 30.0 & First \\
\hline 4 years & Day care or home & $24^{\star}$ & 38.3 & First $\dagger$ \\
\hline 5 years & Day care or home & $46^{\star}$ & 41.7 & First $\dagger$ \\
\hline 6 years & Day care or home & $59^{\star}$ & 13.3 & Second \\
\hline $7-12$ years & Elementary schools & High & 12.5 & First $\ddagger$ \\
\hline $13-19$ years & Various schools & High & 270.7 & First $\ddagger \complement$ \\
\hline $20-29$ years & Work & - & 18.0 & - \\
\hline $30-39$ years & Work & - & 1.5 & - \\
\hline 40 - years & Work & - & 0.1 & - \\
\hline Total & - & - & 25.69 & - \\
\hline
\end{tabular}

*Among 45000 vaccinees in 1983 . †Those over 18 months of age by 1983 were exceptionally allowed to be vaccinated. $¥ 70000$ non-vaccinated children aged $7-10$ years were traced and vaccinated in 1985, and the 11-13 year old girls' monovalent rubella programme became an MMR programme targeted at boths sexes in 1988. $\$ 19-20$ year old conscripts vaccinated since 1986 . ๆ451 diagnoses made in commercial laboratories not included.

emerged 100 kilometers to the north. The epidemic shifted both north and south; it peaked in northeast Finland in February 1989, then continued southeast, and the southern-most regions were affected in April-May 1989.

During the outbreak, 1748 measles cases were reported; 1297 of them were confirmed by uniform serological criteria in the National Public Health Institute and the remainder by varying criteria in virology laboratories of five universities. The epidemic is depicted by a slowly propagating curve of measles cases with some peaks.

CASES

There were 153 serologically confirmed and vaccinated measles cases during the epidemic, whose mean age was 10.1 years, range 2 to 22 . They were identified and confirmed as follows. A nationwide $M M R$ vaccine failure notification programme operating since 1982 in the government reference laboratory only, provided a series of 85 measles cases. ${ }^{6}$ Single monovalent measles vaccine failures were not notified to this programme. A serological surveillance programme for measles was launched in 1987 and the National Public Health Institute provided diagnostic services free of charge to both public and private health sectors, ${ }^{6}$ and gave 68 mainly monovalent vaccinated measles cases for this study. Cases were included when the time from the last vaccination to the onset of symptoms exceeded 90 days.

The surveillance procedures required that whenever measles was suspected, paired serum samples of the case were sent for serological confirmation to the National Public Health Institute. Measles was defined as a fourfold increase in IgG antibodies in paired serum samples using a haemagglutination inhibition technique. ${ }^{10}$ If only one sample was available, diagnosis required an increase in specific IgM antibodies by enzyme immunoassay (EIA) (Enzygnost IgM/EIA Behringwerke, Marburg, Germany). All cases were IgM positive.

CONTROLS

The original series comprised 518 and the final series with complete data 453 controls who did not catch measles during the epidemic. They were selected as follows. At first, confirmed measles cases were removed from the sampling frame. Then the controls were selected from the same age range as the cases, including those who had passed first vaccination age (that is, 19 months) 90 days before the epidemic period. The controls' age range definition was in practice too wide and 24 controls originally chosen in the two control series appeared too young. They were not approached.

Four controls from each case's municipality, and additional 258 controls from high attack rate municipalities (at least 600 per 100 000) were randomly selected from the National Population Registry. For example, if there were four vaccination failures in a low attack rate municipality (<600 per 100000$) 16$ controls were randomly picked.

At the time of control sampling, 65 vaccine failures identified by the serological surveillance programme were available and confirmed. Additional 85 cases from the vaccine failure notification programme (and three cases from the serological surveillance programme) were later provided by serological data. Their area of residence satisfied the sampling criteria. Furthermore, in both series the vaccination status of controls was almost identical (data not shown) because of the uniform nature of the Finnish vaccination system. Thus, selection of additional controls was considered unnecessary.

Forty one controls had either not returned questionnaire or their health card could not be located in school (see later). Thus, the size of the final combined control series was 453 cases; their mean age was 10.0 years, range 2 to 22. Among the controls, 80 teenagers and young adults had a previous history of measles irrespective of the vaccination status (table 2),

Table 2 Relative risk (RR) of measles among once and twice vaccinated compared with three times vaccinated in Finland during the 1988-89 epidemic

\begin{tabular}{|c|c|c|c|c|c|c|c|}
\hline \multirow{2}{*}{$\begin{array}{l}\text { Prior measles } \\
\text { history }\end{array}$} & \multirow[b]{2}{*}{ Vaccinated } & \multirow[b]{2}{*}{ Cases } & \multirow[b]{2}{*}{ Controls } & \multicolumn{2}{|c|}{ Crude } & \multicolumn{2}{|c|}{ Adjusted ${ }^{\star}$} \\
\hline & & & & $\overline{R R}$ & $(95 \% C I)$ & $\overline{R R}$ & $(95 \% C I)$ \\
\hline No & Thricet & $3(2) \ddagger$ & 64 & 1.0 & - & 1.0 & - \\
\hline No & Twice & $10(4) \ddagger$ & 93 & 2.3 & $(0.6,11.0)$ & 7.1 & $(2.1,19.9)$ \\
\hline No & Once & $140(12) \ddagger$ & 192 & 15.6 & $(4.9,78.6)$ & 16.3 & $(2.6,138.5)$ \\
\hline Yes & Any & - & 80 & - & & - & \\
\hline No & No & $1053(13) \rrbracket$ & 24 & - & & - & \\
\hline Total & & 1206 & 453 & - & & - & \\
\hline
\end{tabular}

*Averaged over five age strata, and all vaccinations given $<14$ months of age omitted. †Reference category for relative risk estimates. $\neq$ In parentheses the number of reported failures from one municipality with the highest attack rate $\left(2200 / 10^{5}\right)$ and very low vaccine efficacy even among the revaccinees ${ }^{14}$. $\$ 1053$ non-vaccinated measles cases were reported to the serological surveillance programme in the 2-22 year age range. 
24 of the controls did not have a measles vaccination history nor previous measles history.

DATA ON CASES AND CONTROLS

The vaccination status and measles history of each case was checked from health cards by nurses or physicians at the case's health care centre or school, which was derived from the surveillance programmes.

The health centre or school of controls was not available from registries, but the control's address was provided by the Population Registry. Data on vaccination status and measles history of the controls were obtained by mail questionnaire and checked from the vaccination card at home. In a case of non-response or lost card, the nearest health care centre or school was approached for a photocopy of the health card. The data were based on the card at home in $71 \%$, a photocopy of the card from health centre or school in 14\%, and $7 \%$ of subjects were sure about their vaccinations and gave exact dates. The response rate for the controls was $92 \%$.

INFECTION PRESSURE

Average infection pressure in a municipality during the outbreak was calculated by dividing the number of measles cases by the population. The high pressure criteria (attack rate $>600$ / $10^{5}$ ) used in selection of controls and subsequent data analyses correspond to the attack rate during the peak years before the vaccination programmes. ${ }^{4} 6$

The infection pressure on an individual cannot be measured directly. Daily contacts with other children allow crude estimates of the number of possible virus exposures according to the classic Reed-Frost model. ${ }^{11}$ Data on daily contacts were not collected for the cases and controls. A notion of infection pressure was obtained by estimating it indirectly for pre-school children by each year of age from a separate national sample of 45000 children whose mothers reported the number of daily child contacts to nurses during visits in 1983 .

\section{STATISTICAL METHODS}

Relative risks of measles among once and twice vaccinated compared with thrice vaccinated, and time and vaccination age related relative risks were estimated by odds ratios, and the corresponding confidence intervals calculated by an exact method. ${ }^{12}$ All analyses dealing with additional protection by revaccinations (only controls' vaccinations that preceded the outbreak period were considered) were stratified by low $\left(<600 / 10^{5}\right)$ or high $\left(>600 / 10^{5}\right)$ infection pressure areas and by different daily attendance groups (table 1) to evaluate confounding resulting from differences in exposure. Daily attendance groups were stratified as follows: preschool children, three two year age categories within elementary schools, and children and young adults no longer in elementary schools. Not a single twice MMR vaccinated case among most intermingling 6 year olds (table 1) was reported within the youngest age strata. Few older children ( $>12$ years) were twice vaccinated and even they got additional protection from revaccination. Crude and Mantel-Haenszel age adjusted ${ }^{13}$ relative risks of once and twice compared with thrice vaccinated are presented omitting all cases and controls who received the first monovalent vaccination before 14 months of age. Finally cases from one municipality where even revaccinees had high measles risk (up to $80 \%$ ) were omitted because of the very special nature of this particular setting. ${ }^{14}$

Time since vaccination among controls was calculated to the median day of the outbreak. Analyses dealing with time since the vaccination and time between vaccinations were restricted to the MMR programme (only once vaccinated included) to avoid effect modification because of wild virus exposure, ${ }^{4615}$ and possible different immunogenic ${ }^{16}$ and storage ${ }^{17-20}$ properties, and because of previous low vaccination age. Twenty four of the 55 cases immunised with solely monovalent measles vaccine had received it in 1975 or 1976 before 14 months of age.

\section{Results}

Children aged 10-13 months and teenagers had the highest attack rates (table 1).

Those once vaccinated against measles in mono- or trivalent form had a 15.6 times higher risk of the disease (95\% CI 4.9, 78.6) during the outbreak compared with those thrice vaccinated (table 2). Comparing once vaccinated to two and three times vaccinated combined, the relative risk was $8.8(4.7,17.6)$. Restricting the analyses to those immunised by trivalent MMR vaccine since 1982 , once vaccinated subjects had a $5.6(2.1,18.5)$ higher risk of measles compared with the twice vaccinated (none were vaccinated three times). Adjustment over five age groups and restricting analyses to those vaccinated after 14 months of age did not materially change the results. When those cases who had received their first vaccination at less than 14 months of age were omitted, once vaccinated had $4.0(1.2,16.6)$ higher age adjusted measles risk compared with twice vaccinated.

When cases from one particular municipality where even revaccinees had high measles risk and also cases who had received their first vaccination at less than 14 months of age were omitted, once vaccinated had $17.8(2.8,67.8)$ higher measles risk compared with twice vaccinated after age adjustment. Only one thrice vaccinated case who had received her first vaccination at 11 months of age was reported outside the high risk municipality.

The risk of contracting measles increased linearly with time from vaccination among preschool children, but a weaker and statistically non-significant association emerged among school children. Pre-school children who were vaccinated more than four years previously had a $4.2(1.4,13.1)$ times higher measles risk compared with those vaccinated within the two years before outbreak.

Twice MMR vaccinated cases (all five cases were from the previously mentioned municipality where even revaccinees had measles risk) had a 1.6 years $(0.4,2.8)$ shorter mean interval 
between vaccinations than the controls even when restricting comparison within elementary school children. When the time interval between vaccinations was arbitrarily divided into less than 2.5 years and 2.5 or more, the more closely revaccinated had a 22.8 (2.0, 1102.2) times higher measles risk compared with those revaccinated more apart. Thus, the twice MMR vaccinated individuals had complete protection in low attack rate areas. Almost all the twice MMR vaccinated in Finland were in low attack rate elementary schools during the 1988-89 epidemic season.

When restricting analyses among once inoculated monovalent vaccine recipients who all were no longer in low attack rate elementary schools, those vaccinated before 14 months of age had $2.7(1.0,8.0)$ higher risk of measles compared with those vaccinated after 14 months of age.

When taking only those age cohorts that first received monovalent measles vaccine and who were once revaccinated with $M M R$, those who were first vaccinated before 14 months of age had $3.5(0.5,25.2)$ times higher measles risk compared with those who received their first inoculation after 14 months of age.

\section{Discussion}

The strength of this study compared with previous outbreak research ${ }^{19-42}$ is the large number of serologically confirmed vaccine failures and the large proportion of twice and even thrice vaccinated subjects (about 170000 ) in the population during an outbreak in an environment practically free of natural boosters for years. This is the first study directly assessing the effect of time between successive measles vaccinations, though the small number (five) twice vaccinated MMR failures all originated in one municipality with exceptional circumstances.

The validity could be questioned if twice and thrice vaccinated measles cases were underreported in vaccine failure surveillance. Had measles cases been sporadic this might have been a problem, as the reporting physician might not have made the correct diagnosis when the subject had a history of two or even three measles vaccinations. In an obvious outbreak situation, however, this type of reporting bias cannot explain our results. Essential non-response bias is unlikely as we had a very high response rate throughout. Information bias is excluded by the serological confirmation of cases and numerous cross checkings from previous double records of the vaccinations. Sound internal validity of the study is also reflected by the fact that low vaccination age not only among once vaccinated $d^{91-24} 2830-373941$ but also among revaccinated ${ }^{42}$ predicted vaccination failure.

The superiority of the two dose over the one dose strategy has been indirectly predicted from ecological, ${ }^{44}$ and quasi experimental data, ${ }^{45}$ and indirect individual level immunological data. ${ }^{37}$ Conclusive evidence that revaccinated individuals have lower measles attack rates has so far been lacking, ${ }^{1}$ though many outbreak reports suggest this interpreta- tion. 22 29-31 354142 Our study shows that routine revaccination gives more complete protection, even when the first vaccination is given after 14 months of age.

The common belief that successful measles vaccination induces lifelong immunity ${ }^{46-49}$ has been the prevailing doctrine on which many national $^{4050-52}$ and especially international ${ }^{46}$ recommendations were based. This belief is based on historical analogy: after measles had been absent for a long time in Faroe Islands those who had had measles decades ago were not attacked..$^{53}$ Excluding isolated areas, a person's lifetime number of measles exposures used to be around 15 in the prevaccination era. ${ }^{54}$ Vaccine induced antibody titres decline in low attack rate conditions, ${ }^{9} 37484955-57$ whereas in reported measles exposures in the United Kingdom no such effect has been observed. ${ }^{51}{ }^{52}$

The additional protection from revaccination is achieved by correcting either primary or secondary vaccine failures, or both. A longer time since single vaccination increased measles risk among pre-school children, suggesting waning immunity, though this association might be explained by a concomitant increase in the number of daily contacts and thus a greater possibility of catching measles. The latter interpretation is supported by the fact that time since vaccination did not clearly explain vaccine failure among older school children. It is however, possible that we were undersampling secondary vaccine failures, because all cases were $\operatorname{IgM}$ positive. This is thought to indicate virginity to infection, ${ }^{58}{ }^{59}$ though this has been questioned. ${ }^{60-63}$

Many studies have found that time since vaccination increases the risk of measles vaccine failure, ${ }^{21-23} 25-2729-32353641$ but this may have been because of the introduction of the new heat stabiliser in measles vaccines after $1979^{917-2036}$ or to previous low vaccination age. $^{242741}$ Many studies 2833383958 have not found that time since vaccination predicts vaccine failure. So far some circumstantial $^{915} 565765$ and even some direct ${ }^{7}{ }^{80}$ evidence implies that waning vaccine induced immunity might become a true problem in conditions without natural boosters.

Vaccine induced virus replication is considered responsible for the defence response against measles. ${ }^{66}$ Replication is probably weak or absent with high antibody titres, as high maternal or intentionally administered antibody titres interfere with measles vaccination. ${ }^{67}$ It could be that antibody levels have to decline after measles vaccination to achieve a proper protection by revaccination, and this could explain why a short interval between vaccinations increased the risk of measles compared with a longer interval. Indeed, a 10 year interval has been shown to yield a more comprehensive and sustained immunological response compared with a short interval. ${ }^{56}$ Recent observational data from the US have challenged this. ${ }^{42}$ Obviously the fact that the five twice MMR vaccinated failures of whom four of five had a shorter than 2.5 year time period between vaccinations originated from one 
municipality ${ }^{14}$ with very special circumstances weakens our ability to make valid inferences about time periods between vaccinations.

This study further strengthens our belief that the key to the success ${ }^{4-6}$ along with high achieved coverage $e^{5}$ has been revaccination. In 1996 not a single measles case was diagnosed ${ }^{68}$ from over 1000 studied serum samples, although almost two million Finns travel abroad annually and hundreds of thousands of tourists from high attack rate areas in the old Soviet Union visit Finland each year. All suspected measles cases require paired serological testing in Finland. Whether revaccination also boosts immunity is to be answered by future studies.

Funding: this work has been supported by Ministry of Health and Social Affairs of Finland and Merck and Co.

The authors acknowledge Professor Kari Penttinen who recommended with farsight that the Finnish Government adopt a two dose vaccination policy against measles, mumps, and rubella in the late $1970 \mathrm{~s}$ and professor Kari Cantell for his leadership role in the project.

1 US Preventive Services Task Force. Immunizations and chemoprophylaxis. Childhood immunizations. In: DiGuiseppi C, Atkins D, Woolf SH, eds. Guide to clinical preventive services. 2nd ed. Baltimore: Williams and Wilkins, 1996:767-90.

2 World Health Organization. Expanded Programme on Immunization (EPI) - Measles Control in the WHO African Region. Weekly Epidemiological Record. Number 26, African Region. Weekly

3 Brunell PA, Weigle K, Murphy D, et al. Antibody response following measles-mumps-rubella vaccine under conditollowing measles-mumps-rubella vaccine under

4 Peltola H, Karanko V, Kurki T, et al. Rapid effect of endemic measles, mumps, and rubella of nationwide vaccination programme in Finland. Lancet 1986;i:137-9.

5 Paunio $M$, Virtanen $M$, Peltola $H$, et al. Increase of vaccination coverage by mass media and individual approach Intensified measles, mumps, and rubella prevention program in Finland. Am ₹ Epidemiol 1991;133:1152-60.

6 Peltola $\mathrm{H}$, Heinonen OP, Valle $\mathrm{M}$, et al. The elimination of indigenous measles, mumps, and rubella by a 12 -year, twodose vaccination program. N Engl f Med 1994;331:1397402

7 Reyes MA, de Borrero MF, Roa J, et al. Measles vaccine failure after documented seroconversion. Pediatr Infect Dis $\mathcal{F}$ 1987;6:848-51.

8 Mathias RG, Meekison WG, Arcand TA, et al. The role of secondary vaccine failure in measles outbreaks. Am f Public Health 1989:79:475-8.

9 Markowitz LE, Preblud SR, Fine PEM, et al. Duration of live measles vaccine-induced immunity. Pediatr Infect Dis $\mathcal{F}$ 1990;9:101-10.

10 Gershon AA, Krugman S. Measles virus. In: Lennette EH, Schmidt NJ, eds. Diagnostic procedures for viral, rickettsial and chlamydial infections. 5th ed. Washington, DC: American Public Health Association, 1979:685-6.

11 Fox JP, Elveback L, Scott W, et al. Herd immunity: basic concept and relevance to public health immunization practices. Am f Epidemiol 1971;94:179-89.

12 Mehta CR, Patel NR, Gray R. Computing of an exact confidence interval for the common odds ratio in several $2 \times 2$ contingency tables. Fournal of the American Statistical Association 1985;80:969-73.

13 Schlesselman JJ. Basic methods of analysis. In: Case-control studies. Design, conduct, analysis. New York: Oxford University Press, 1982:171-226.

14 Paunio M, Peltola H, Valle M, et al. Explosive school-based measles outbreak-intense exposure may have resulted in
high risk, even among revaccinees. Am 7 Epidemiol (in high rist.

15 Pedersen IR, Modhorst CH, Glikmann G, et al. Subclinical infection in vaccinated seropositive individuals in Arctic Greenland. Vaccine 1989;7:345-8.

16 Boulianne N, De Serres G, Ratnam S, et al. Measles, mumps, and rubella antibodies in children 5-6 years after immunization: Effect of vaccine type and age at vaccination. Vaccine 1995;13:1611-16.

17 André FE. Thermodegradation of lyophilized measles vaccines. Rev Infect Dis 1983;5:532-4.

18 Klamm H, Pollex G, Henning U. Thermal inactivation of different measles virus strains. Acta Virol 1991;35:200-2.

19 Lerman SJ, Gold E. Measles in children previously vaccinated against measles. $\mathcal{F} A M A$ 1971;216:1311-14

20 McIntyre RC, Preblud SR, Polloi A, et al. Measles and measles vaccine efficacy in a remote island population. Bull World Health Organ 1982;60:767-75.

21 Rawls WE, Rawls ML, Chernesky MA. Analysis of a measles epidemic; possible role of vaccine failures. Can Med Assoc F 1975;113:941-4.
22 Shasby DM, Shope TC, Downs H, et al. Epidemic measle in a highly vaccinated population. $N$ Engl f Med 1977;296: $585-9$

23 Marks JS, Halpin TJ, Orenstein WA. Measles vaccine efficacy in children previously vaccinated at 12 months of age. Pediatrics 1978;62:955-60

24 Shelton JD, Jacobson JE, Orenstein WA, et al. Measles vaccine efficacy: Influence of age at vaccination vs. duration of time since vaccination. Pediatrics 1978;62:961-4.

25 Riley EC, Murphy G, Riley RL. Airborne spread of measles in a suburban elementary school. Am $\mathcal{F}$ Epidemiol 1978;107:421-32

26 Center for Disease Control and Prevention. Measles outbreak among vaccinated

27 Wassilak SGF, Orenstein WA, Strickland PL, et al. Continuing measles transmission in students despite a school-based outbreak control program. Am f Epidemiol 1985;122:20817.

28 Hull HF, Montes JM, Hays PC, et al. Risk factors for meales vaccine failure among immunized students. Pediatrics 1985;76:518-23

29 Davis RM, Whitman ED, Orenstein WA, et al. A persistent outbreak of measles despite appropriate prevention and control measures. Am f Epidemiol 1987;126:438-49.

30 Nkowane BM, Bart SW, Orenstein WA, et al. Measles outbreak in a vaccinated school population: Epidemiology, chains of transmission and the role of vaccine failures. Am F Public Health 1987;77:434-8.

31 Hutchins SS, Markowitz LE, Mead P, et al. A school-based measles outbreak: The effect of a selective revaccination policy and risk factors for vaccine failure. Am F Epidemiol 1990;132:157-68.

32 Mast EE, Berg JL, Hanrahan LP, et al. Risk factors for measles in a previously vaccinated population and costeffectiveness of revaccination strategies. $7 A M A$ 1990;264. 2529-33.

33 Hersch BS, Markowitz LE, Hoffman RE, et al. A measles outbreak at a college with a prematriculation immunization equirement. Am f Public Health 1991;81:360-4

34 Osterman JW, Melnychuk D. Revaccination of children during school-based measles outbreaks: Potential impact of a new policy recommendation. Can Med Assoc f 1992;146: 929-36.

35 Robertson SE, Markowitz LE, Berry DA, et al. A million dollar measles outbreak - epidemiology, risk factors, and a selective revaccination strategy. Public Health Rep 1992;107: 24-31.

36 Yuan L. Measles outbreak in 31 schools: risk factors for vaccine failure and evaluation of a selective revaccination strategy. Can Med Assoc F 1994;150:1093-8.

37 Gustafson TL, Lievens AW, Brunell PA, et al. Measles outbreak in a fully immunized secondary-school population. $N$ Engl F Med 1987;316:771-4.

38 Markowitz LE, Preblud SR, Orenstein WA, et al. Patterns of transmission in measles outbreaks in the United States, 1985-1986. N Engl f Med 1989;320:75-81.

39 Chen RT, Goldbaum GM, Wassilak SGF, et al. An explosive point-source measles outbreak in a highly vaccinated population. Am f Epidemiol 1989;129:173-82.

40 Fescharek R, Quast U, Maass G, et al. Measles-mumps vaccination in the FRG: An empirical analysis after 14 years of use. I. Efficacy and analysis of vaccine failures. Vaccine 1990;8:333-6.

41 Agocs MM, Markowitz LE, Straub I, et al. The 1988-1989 measles epidemic in Hungary: Asses

42 Poland GA, Jacobsen RM, Thampy AM, et al. Measles reimmunization in children seronegative after initial immunization $7 A M A$ 1997;277:1156-8.

43 Guris D, Mccready J, Watson JC, et al. Measles vaccine effectiveness and duration of vaccine-induced immunity in effectiveness and duration of vaccine-induced immunity in Pediatr Infect Dis ₹ 1996;15:1082-6.

44 Tulchinsky TH, Ginsberg GM, Abed Y, et al. Measles conrol in developing and developed-countries: The case for a 2-dose policy. Bull World Health Organ 1993;71:93-103.

45 Crawford GE, Gremillion DH. Epidemic measles and rubella in air force recruits: impact of immunization. $f$ Infect Dis 1981;144:403-10.

46 Rosenthal SR, Clements CJ. Two-dose measles vaccination schedules. Bull World Health Organ 1993;71:421-8.

47 Anderson RM, May RM. Directly transmitted infectious diseases: control by vaccination. Science 1982;215:105360.

48 Krugman S, Giles JP, Friedman H, et al. Studies on immunity to measles. $\mathcal{F}$ Pediatr 1965;66:471-88.

49 Krugman S. Further-attenuated measles vaccine: characteristics and use. Rev Infect Dis 1983;5:477-81.

50 Feldman W. Measles vaccination policy. Can f Public Health 1992;83:108.

51 Miller C. Live measles vaccine: A 21 year follow up. BMF 1987;295:22-4.

52 Ramsay MEB, Moffatt D, O'Connor M. Measles vaccine: A 27-year follow-up. Epidemiol Infect 1994;112:409-12.

53 Panum PL. Observations made during the epidemic of measles on the Faroe Islands in the year 1846. Medical Classics 1939;3:829-86.

54 Hethcote HW. Measles and rubella in the United States. Am Epidemiol 1983;117:2-13.

55 Brown P, Gajdusek CD, Tsai T. Persistence of measles antibody in the absence of circulating natural virus five years after immunization of an isolated virgin population with Edmonston B vaccine. Am f Epidemiol 1969;90:514-18. 
56 Bin D, Zhihui C, Qichang L, et al. Duration of immunity following immunization with live measles vaccine: 15 years of observation in Zhejiang Prov Prgan 1991;69:415-23.

57 Cote TR, Sivertson D, Horan JM, et al. Evaluation of a 2-dose measles, mumps, and rubella vaccination schedule in a cohort of college athletes. Public Health Rep 1993;108: $431-5$

58 Edmonson MB, Addiss DG, McPherson T, et al. Mild measles and secondary vaccine failure during a sustained outbreak in a highly vaccinated population. $f A M A$ 1990;263:2467-71.

59 Ozanne G, D’Halewyn M-A. Secondary immune response in a vaccinated population during a large measles epidemic. 7 Clin Microbiol 1992;30:1778-82.

60 Chen RT, Markowitz LE, Albrecht P, et al. Measles antibody: Reevaluation of protective titers. 7 Infect Dis 1990;162:1036-42.

61 Erdman DD, Heath JL, Watson JC, et al. Immunoglobulin $\mathrm{M}$ antibody response to measles virus following primary and secondary vaccination and natural virus infection. $f$ Med Virol 1993;41:44-8.
62 Hidaka Y, Aoki T, Akeda $\mathrm{H}$, et al. Serological and clinical characteristics of measles vaccine failure in Japan. Scand $\mathcal{F}$ characteristics of measles vacc
Infect Dis 1994;26:725-30.

63 Erdman DD, Heath JL, Watson JC, et al. Immunoglobulin $\mathrm{M}$ antibody response to measles virus following primary and secondary vacination and natural virus infection. $\mathcal{F}$ Med Virol 1993;41:44-8.

64 Aaby P, Bukh J, Leeroy J, Lisse IM, et al. Vaccinated children get milder measles infection: A community study from Guinea-Bissau. F Infect Dis 1986;154:858-63.

65 Gray D, Skarvall H. B-cell memory is short-lived in the absence of antigen. [Letter]. Nature 1988;336:70-3.

66 Melnick JL. Virus vaccines: principles and prospects. Bull World Health Organ 1989;67:105-12.

67 Martin CM, Manfredonia SJ, Webb NC, et al. Controlled trial of live measles vaccine: Effects of age, history of measles in siblings, prevaccine antibody, and human gammaglobulin on symptomatic and immune responses. $\mathrm{Am} \mathcal{F}$ Pediatr Dis Child 1963;106:267-79.

68 Peltola H, Davidkin I, Valle M, et al. No measles in Finland. Lancet 1997;350:1364-5. 